\title{
PENINGKATAN PENGETAHUAN LANSIA TENTANG MENOPAUSE MELALUI KEGIATAN KONSELING DI GOR CANDRABAGA KOTA BEKASI TAHUN 2019
}

\section{OLEH :}

\author{
Hainun Nisa, SST., M. Kes, ${ }^{(1)}$ Linda K Telaumbanua, SST.,M.Keb ${ }^{(2)}$ \\ Nurmah, SST., M. Kes ${ }^{(3)}$ Puri Kresna Wati, SST., M. KM ${ }^{(4)}$ \\ Evi Nur Akhiriyanti, SST., MN.Mid ${ }^{(5)}$ Rupdi, SST., M.Kes ${ }^{(6)}$ \\ hainunnisa78@gmail.com, telaumbanua_linda@yahoo.com, Purri409@gmail.com \\ evi.akhiriyanti@gmail.com, rupdia715@gmail.com, fawfil1507@gmail.com
}

\section{A. DASAR PEMIKIRAN}

Menopause menunjukkan suatu keadaan berhentinya menstruasi. Sebelum seorang perempuan memasuki menopause akan mengalami perubahan fisik dalam tubuhnya, yaitu produksi hormon menurun, menstruasi tidak teratur dan keadaan fertilitas diganti dengan infertilitas. Menjelang memasuki masa menopause, banyak perempuan mengalami sejumlah gejala klinis dan psikologis yang mengganggu aktivitas sehari-hari serta menimbulkan dampak negatif terhadap kualitas hidup dan rasa percaya diri (Baziad, 2003)

Menurut Depkes RI (2009) hingga saat ini wanita Indonesia yang memasuki masa menopause sebanyak $7,4 \%$ dari populasi. Jumlah tersebut meningkat menjadi $11 \%$ pada 2005. Kemudian naik lagi sebesar $14 \%$ pada 2015. Meningkatnya jumlah tersebut, sebagai akibat bertambahnya populasi penduduk usia lanjut dan tingginya usia harapan hidup dibarengi membaiknya derajat kesehatan masyarakat. Jumlah dan proporsi penduduk wanita yang berusia diatas 50 tahun dan diperkirakan memasuki usia menopause dari tahun ke tahun juga mengalami peningkatan yang sangat signifikan. Pada Sensus Penduduk tahun 2000 jumlah wanita berusia diatas 50 tahun baru mencapai 15,5 juta orang atau $7,6 \%$ dari total penduduk, sedangkan tahun 2020 jumlahnya diperkirakan meningkat menjadi 30,0 juta atau $11,5 \%$ dari total penduduk (Depkes RI, 2005).

Menopause merupakan fase dimana wanita tidak mengalami menstruasi. Seringkali wanita menghadapi menopause dengan rasa cemas dan takut karena memasuki usia tua dan sudah tidak dapat melahirkan anak Akibat yang ditimbulkan dari keadaan ini menurunnya hormon estrogen, hormon progesteron dan hormon seks dapat menimbulkan gejala fisik yang mungkin dialami saat mencapai masa menopause yakni berupa rasa panas yang tiba - tiba menyerang bagian atas tubuh, keluar keringat yang berlebihan pada malam hari, sulit tidur, iritasi pada kulit, gejala pada mulut dan gigi, kekeringan vagina, kesulitan menahan buang air kecil, dan peningkatan berat badan (Intan, 2017)

Selain itu, menopause merupakan fase dalam kehidupan seorang wanita yang ditandai dengan berhentinya masa subur dan merupakan peristiwa alamiah pada setiap wanita. Banyak wanita yang merasa khawatir menghadapi menopause, karena mereka 
beranggapan bahwa wanita yang berusia lanjut atau yang akan mengalami menopause hidupnya akan kurang sehat, kurang bugar, tidak cantik lagi dan cepat marah (Rebeca, 2006)

Untuk mengurangi kecemasan lansia dalam menjalani masa menoupause STIKes medistra Indonesia melaksanakan kegiatan edukasi kesehatan dalam rangka peringatan Hari Kesehatan Nasional tahun 2019 melalaui kegiatan pengabdian kepada masyarakat dengan judul " Peningkatan pengetahuan lansia tentang menopause melalui kegiatan konseling di GOR Candrabaga Kota Bekasi Tahun 2019"

\section{B. TUJUAN}

1. Tujuan Umum:

Meningkatnya pengetahuan lansia tentang menopause di GOR Candrabaga Kota Bekasi Tahun 2019

2. Tujuan Khusus:

a Meningkatnya pengetahuan lansia tentang pengertian menopause di GOR Candrabaga Kota Bekasi Tahun 2019

b Meningkatnya pengetahuan lansia tentang perubahan pada masa menopause di GOR Candrabaga Kota Bekasi Tahun 2019

c Meningkatnya pengetahuan lansia tentang kebutuhan pada menopause di GOR Candrabaga Kota Bekasi Tahun 2019

\section{BENTUK KEGIATAN}

Bentuk kegiatan yang dilaksanakan adalah kegiatan edukasi kesehatan dengan menyediakan layanan konseling di GOR Candrabaga Kota Bekasi dalam rangka peringatan hari Kesehatan Nasional

\section{SASARAN}

Sasaran dalam kegiatan ini adalah lansia yang mengunjungi GOR Candrabaga Kota Bekasi yaitu sebanyak 25 orang

\section{E. TEMPAT DAN WAKTU}

Kegiatan edukasi kesehatan ini dilaksanakan di Candrabaga Kota Bekasi pada tanggal 24 November tahun 2019

\section{F. PELAKSANA}

Pelaksana kegiatan ini adalah 5 (lima) orang dosen dan 6 (enam) orang mahasiswa STIKes Medistra Indonesia

\section{G. HASIL KEGIATAN \\ DAN PEMBAHASAN}

\section{1) Pemahaman lansia tentang menopause}

Tahapan ini merupakan tahapan awal kegiatan abdimas yang dilakukan, dimana lansia yang berkunjung ke pameran yang diselenggarakan oleh STIKes Medistra Indonesia diberilan dulu pertanyaan tentang pemahaman sasaran tentang menopause

Hasil survei pemahaman sasaran tentang defenisi menopause adalah 21 $(84 \%)$ orang menyatakan bahwa menopause adalah proses berhentinya menstruasi, sedangkan $4(16 \%)$ orang sasaran menyatakan bahwa menaupause adalah kondisi perempuan tidak bisa hamil lagi

Hal ini sesuai dengan teori yang menyebutkan bahwa dalam pandangan medis, menopause didefinisikan sebagai masapenghentian haid untuk selamanya. Menopause merupakan saat terjadinya haidatau menstruasi terakhir (Prawirohardjo, 2007).

Menopause juga bisa diartikan masa berhentinya menstruasi untuk selamanya biasanya menopause terjadi padawanita 45-55 tahun. Diagnosis menopause dibuat setelah berhenti menstruasi kurang lebih satu tahun, 
berhentinya menstruasi dapat didahului oleh siklus menstruasi yang panjang dengan pendarahan yang berkurang. Umur waktu terjadinya menopause bisa dipengaruhi oleh keturunan, kesehatan, dan polahidup (Andira, 2010)

\section{2) Pemahaman tentang perubahan masa menopause}

Dari survei yang dilakukan kepada 25 lansia pengunjung pameran didapatkan data bahwa 16 (64\%) lansia menyebutkan bahwa perubahan tanda menopause selain berhentinya menstruasi adalah sulit tidur dan penurunan libido (gairah seksual

Sedangkan 9 (36\%) lansia yang berkunjung ke pameran menyatakan perubahan pada masa menopause adalah memiliki kecemasan tinggi, tidak percaya diri

Menurut Mulyani (2013), pada masa menopause wanita akan mengalami perubahan-perubahan diantaranya:

Adapun tanda-tanda perubahan emosi yang mungkin terjadi pada seorang wanita yang mengalami menopause menurut Pieter \& Lubis (2010) diantaranya:

a) Ingatan menurun

Gejala menurunnya ingatan terlihat bahwa sebelum menopause wanita masih begitu mudah untuk mengingat. Akan tetapi, sesudah mengalami menopause terjadi kemunduran dalam mengingat bahkan mereka sering lupa terhadap halhal kecil dan sederhana.

b) Kecemasan ibu yang mengalami menopause menjadi seorang yang mudah mengalami rasa cemas. Kecemasan ini timbul sebagai akibat seringnya kekhawatiran yang menghantui dalam menghadapi situasi yang sebelumnya tidak pernah mereka khawatirkan. kecemasan ini biasanya relatif, artinya kecemasan itu bisa dihilangkan dan ditenangkan. Namun pada sebagian orang kondisi ini tidak mampu dilakukan. Adapun gejala-

c) Mudah tersinggung

Gejala ini lebih mudah dilihat jika kita bandingkan dengan perasaan cemas. Wanita menopause lebih menunjukkan sikap mudah tersinggung dan marah. Hal ini mungkin saja disebabkan adanya tingkat kesadaran yang luar biasa dialami mereka. Perasaan mereka begitu sangat sensitif terhadap sikap dan perilaku orang-orang di lingkungan sekitarnya. Kondisi ini akan sangattampak manakala mereka mempersepsikan perilaku itu secara negatif dan menyinggung dirinya.

d) Stress Respons-respons stres pada wanita menopause begitu beragam dan terkadang bersifat kronis. Secara psikologis sumber-sumber stres wanita menopausetidak bisa diramalkan begitu saja, namun yang bisa terlihat adalah siklus suasana hati, misalnya reaksi marah atau sedih. Faktor-faktor penyebab stres pada wanita menopause yaitu keadaan emosi personalnya dan sikap orang-orang di sekitarnya.

e) Depresi

Dari hasil penelitian menunjukkan bahwa wanita menopause lebih besar dan lebih gampang mengalami depresi dibandingkan dengan rentang kehidupan sebelumnya.

Selain perubahan diatas, terdapat perubahan gairah seksual wanita menopause umumnya disebabkan perubahan kadar hormon dalam tubuh. Saat menopause, kadar hormon estrogen yang memegang peranan penting terhadap fungsi seksual akan mengalami penurunan. 
Efeknya, wanita menopause lebih sulit untuk terangsang dan mengalami orgasme.

Menurunnya kadar hormon estrogen dalam tubuh wanita menopause juga menurunkan aliran darah yang mengalir ke vagina. Efeknya, terjadi penurunan produksi cairan pelumas vagina yang menyebabkan vagina menjadi kering. Kondisi ini membuat hubungan seksual terasa menyakitkan, sehingga membuat wanita menopause enggan untuk melakukan hubungan seksual.

Selain karena perubahan hormon, penurunan gairah seksual wanita menopause juga bisa disebabkan oleh depresi, stres, kecemasan, gangguan tidur, dan gangguan kesehatan tertentu.

Keluhan gairah seksual yang menurun setelah menopause dialami oleh sebagian besar wanita. Namun, ada pula yang gairah seksualnya justru meningkat begitu memasuki masa menopause.

Hal ini dipengaruhi oleh faktor psikis, misalnya karena wanita menopause tidak perlu lagi mencemaskan kehamilan yang tidak diinginkan dan sebagian besar wanita menopause sudah tidak lagi memikul tanggung jawab untuk membesarkan anak. Hal ini menyebabkan wanita menopause menjadi lebih santai dan menikmati hubungan intim dengan pasangannya.

Dalam kegiatan konseling, konselor memberikan tips agar lansia yang mengalami menopause tetap dapat menikmati aktifitas seksualnya dengan hal dibawah ini

Untuk mengatasi perubahan gairah seksual yang terjadi pada wanita menopause, terutama penurunan gairah seks, ada beberapa cara yang bisa dilakukan, yaitu:

\section{Menggunakan cairan pelumas}

Jika penurunan gairah seksual disebabkan oleh vagina kering, Anda dapat menggunakan pelumas agar hubungan seks menjadi lebih nyaman. Namun, hindari penggunaan pelumas yang berbahan dasar minyak (oil-based).

\section{Melakukan olahraga dengan rutin}

Olahraga rutin bisa menjadi salah satu cara untuk mengurangi stres dan memperbaiki suasana hati. Suasana hati yang baik diyakini bisa meningkatkan gairah seksual wanita menopause.

\section{Menjalin komunikasi dengan pasangan}

Penurunan gairah seksual wanita menopause bisa disebabkan oleh kurangnya komunikasi dengan pasangan. Oleh karena itu, bicarakan apa yang Anda dan pasangan inginkan agar hubungan seksual jadi lebih menyenangkan.

\section{3) Pemahaman kebutuhan nutrisi pada masa menopause}

Dalam survey yang dilakukan pada awal sebelum konseling pengunjung lansia memahami bahwa nutrisi yang dibutuhkan saat menopause adalah kacang kedelai Dlam konseling yang dilakukan STIKes Medistra Indonesia dipaparkab beberapa nutrisi yang perlu diketahui oleh lansia yang mengalami menopause adalah sebagai berikut

1.Kalsium 
Pada masa premenopause kalsium mengalami penurunan, kalsium penting untuk kekuatan tulang agar tetap kuat dan sehat berhubungan dengan meningkatnya risiko wanita menopause mengalami osteoporosis.Sumber kalsium yang baik antara lain dari produk susu, misalnya susu, keju, yogurt, kuning telur (Proverawati, 2010).

\section{Vitamin D}

Vitamin D sangat baik untuk membantu penyerapan kalsium pada tulang sehingga baik dikonsumsi bersamaan dengan kalsium untuk menghambat terjadinya osteoporosis. Suplemen vitamin D dan kalsium bisa mengurangi tetapi tidak bisa mencegah terjadinya pengeroposan tulang saat premenopause, menopause, dan pasca menopause (Proverawati, 2010).Sebagian besar vitamin D diperoleh dari kulit kitayang terpapar sinarmatahari, tetapi dalam jumlah kecil akan diperoleh dari makanan yang kita peroleh.Sumber vitamin D yang baik antara lain minyak ikan, ikan sardin,ikan makarel, hati, dan telur (Nirmala,2003).

\section{Vitamin E}

Vitamin E melindungi wanita menopause dari masalah jantung dan juga dapat mengatasi hotflush( rasa panas) dan berkeringatdi malam hari.

VitaminE dapat diperoleh dari makanan seperti kacang-kacangan, biji-bijian, minyaksayur, dan sereal (Nirmala,2003).

\section{Fitoestrogen}

Fitoestrogen terdiri dari 3 komponen utama yaitu isoflavon, coumstan, danlignan.Isoflavon merupakan salah satu fitoestrogen yang banyak
diteliti.Beberapa studi menunjukan fitoestrogen memiliki manfaat berkaitan denganpenyakit kardiovaskuler, osteoporosis, dan gejala-gejala menopause(Proverawati, 2010) .Sumber isoflavon dapat diperoleh darikacang merah, kecambah,atau kedelai (olahan kedelai seperti susu, tahu,tempe). Kedelai dapat memperbaiki lipoprotein dalam darah dan dapat menurunkan kadar kolesterol jahat.(Aqila,2010).

5.Mengkonsumsi makanan yang mengandung serat

Serat penting karena menyerap air dan meningkatkan bakteria yang bermanfaat dalam usus. Proses ini akan membentuk kotoran dalam jumlah besar, dan membuat usus bekerjadenganbaik,serta mengurangi resiko penyakit usus besar.Demikian yang terdapat dalam sayuran segar sepertib ayam, kentang, kol, dan kacang-kacangan (Nirmala, 2003)

Pada akhir kegiatan dibuat kesepakatan antara konselor dengan sasaran abdimas adalah sebagai berikut

Untuk menikmati masa menopause dibutuhkan upaya melalui pola hidup yang sehat dengan membiasakan diri berolahraga serta mengkonsumi makanan yang bergizi serta menikmati aktifitas seksual pada masa menopause

\section{H. KESIMPULAN DAN SARAN \\ Kesimpulan}

Kesimpulan dari kegiatan pengabdian kepada masayarakat ini adalah adanya perubahan pengetahuan sasaran sebelum dan sesudah konseling dan adanya kesepakatan bersama untuk menjalani pola hidup sehat pada masa menopause

\section{Saran}

Bagi petugas kesehatan terutamabidan dan petugas puskesmas diharapkan melakukan 
penyuluhan tentang perubahan fisik dan psikologis yang dialami wanita pada masa menopause, terutama pada wanita yang akan memasuki masa menopause sehingga wanita dapat mengatasi dengan sikap dan tindakan yang baik dan positif pada saat mengalami menopause.

\section{DAFTAR PUSTAKA}

Intan N.H. 2017. Hubungan

TahapanMenopause Pada Wanita

Dengan Tingkat Kecemasan Di Desa Karangtanjung Alian Kebumen.Sekolah Tinggi Ilmu Kesehatan Muhammadiyah Gombong

$\begin{array}{lrr}\text { Supari, } & \text { S., Terjadi } & \text { Pergeseran } \\ \text { Umur } & \text { Menopause } & \text { : }\end{array}$
www.warmasif.co.id/kesehatanonline/mod. php? $\bmod =$ download $\&$ op = visit\&lid=1398, diakses pada tanggal 08 Maret 2009, Yogyakarta.2005

Baziad, A., Menopause dan . Andropause, Jakarta, Yayasan Bina Pustaka Sarwono Prawihardjo, 2003

\section{Depkes. 2005. Terjadi Pergeseran Umur Menopause.} http://www.depkes.go.id/index.php?option =news\&task=viewarticle \&sid=93. (sitasi 19 September 2020).

\section{J DOKUMENTASI}

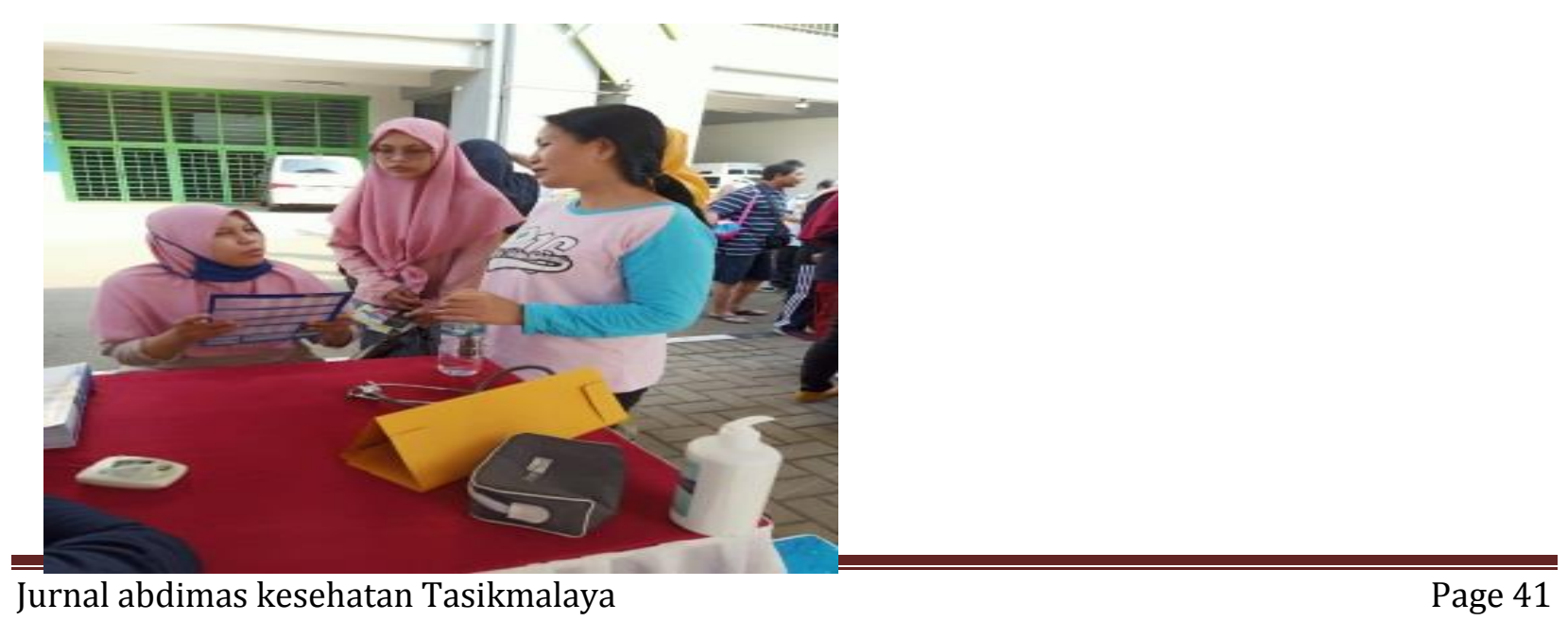

